\title{
Community participation in primary health care projects of the Muldersdrift Health and Development Programme
}

\author{
M Barker \\ Master student, Department of Nursing Education, University of the Witwatersrand, South Africa
}

H Klopper

Professor, School of Nursing Science, North-West University, South Africa

Correspondence address:

Prof Hester Klopper

Private Bag X 6001

School of Nursing Science

North-West University (Potchefstroom

Campus)

Potchefstroom, 2520

Tel: (018) 299-1829/1830

Fax: (018) 2991827

E-mail: hester.klopper@nwu.ac.za
Abstract: Curationis 30(2): 36-47

After numerous teething problems (1974-1994), the Department of Nursing Education of WITS University took responsibility for the Muldersdrift Health and Development Programme (MHDP). The nursing science students explored and implemented an empowerment approach to community participation. The students worked with MHDP health workers to improve health through community participation, in combination with primary health care ( $\mathrm{PHC}$ ) activities and the involvement of a variety of community groups. As the PHC projects evolved over time, the need arose to evaluate the level of community participation and how much community ownership was present over decision-making and resources. This led to the question "What was the level of community participation in PHC projects of the MHDP?" Based on the question the following objectives were set, i.e. i) to evaluate the community participation in $\mathrm{PHC}$ initiatives; ii) to provide the project partners with motivational affirmation on the level of community participation criteria thus far achieved; iii) to indicate to participants the mechanisms that should still be implemented if they wanted to advance to higher levels of community participation; iv) to evaluate the MHDP's implementation of a people-centred approach to community participation in PHC; and v) the evaluation of the level of community participation in PHC projects in the MHDP. An evaluative, descriptive, contextual and quantitative research design was used. Ethical standards were adhered to throughout the study. The MHDP had a study population of twentythree ( $\mathrm{N}=23$ ) PHC projects. A purposive sample of seven PHC initiatives was chosen according to specific selection criteria and evaluated according to the "Criteria to evaluate community participation in PHC projects" instrument (a quantitative tool). Structured group interviews were done with PHC projects' executive committee members. The Joint Management Committee's data was collected through mailed selfadministered questionnaires. Validity and reliability were ensured according to strict criteria. Thereafter results were analysed and plotted on a radiating arm continuum. The following factors had component scores: organization, leadership, resources, management; needs and skills. A spider graph was produced after each factor's continuum was connected in a spoke figuration that brought them together at the base where participation was at its most narrow. The results are presented and a graph and discussion is provided on each of the PHC projects.

The research results indicated that although community participation was broadened, there was minimal success in forcing a shift in power over decision-making and resources. This demonstrated that power over planning and resources should remain in the hands of the partners if community participation was to remain progressive and sustained. Results furthermore indicated that the people-centred approach to community participation enabled participants to broaden community participation. 
With regard to the Joint Management Committee's evaluation of community participation, it was concluded that power over decision-making and resources remained with health professionals rather than with the community, and that a people-centred approach had not been adopted.

\section{Background to the problem}

The University of the Witwatersrand's (WITS) Muldersdrift Health and Development Programme (MHDP) was initiated in 1974 by a group of concerned medical students who responded to the health needs of a deprived community, living in a peri-urban area on the northwestern outskirts of Johannesburg, called Muldersdrift. Unfortunately the student driven programme faltered in 1996 due to lack of donor funding and commitment. While alternative arrangements were bcing investigated, the Department of Nursing Education took over the administration of the programme from 1995 to 1999. A partnership was negotiated between the Gauteng Department of Health's West Rand Regional Office (WRRO), the University of the Witwatersrand (WITS) and the Muldersdrift Community through the Muldersdrift Clinic Committee (MCC). A Joint Management Committee (JMC), with four representatives each from these three partners, was formed. This provided an ideal opportunity for an evaluation of the participation of the community and specifically the MHDP.

Rifkin, Muller and Bichmann (1988:933) clarified the community participation process in the context of Primary Health Care (PHC), defined the concept 'community' and also hinted at the power shifts (empowerment) required for development. They stated: "Community participation is a social process whereby specific groups with shared needs living in a defined geographic area actively pursue identification of their needs, take decisions and establish mechanisms to meet these needs. In the context of PHC, this process is one which focuses on the ability of these groups to improve their health care and by exercising effective decisions to force the shift in resources with a view to achieving equity."

Rifkin (1981:377-386) traced the power shifts that occur with the involvement of laymen in the specialised field of medicine and identified four approaches to community participation in PHC. Rifkin and Cassels (1990:39) summarised the community's role in each of these four approaches to community participation as; compliance in the public health approach; contribution in the health planning approach; control in the selfcare approach, and lastly collaboration with eventual control of activities and resources by the community in the community development approach. One of Rifkin's (1981:377-386) identified approaches i.e. the community development approach evolved into the radical participatory approach, which gained prominence and further developed into even more variants, one of which is the empowerment or 'peoplecentred approach'. The MHDP's Constitution was revised and Clause 3 stated that the 'people-centred approach' to development was chosen to guide the programme partners (University of the Witwatersrand, 1984:2).

The history of the MHDP indicates that the medical students were not very successful in implemention of a 'peoplecentred approach.' That the medical students debated Rifkin's (1981) various approaches to community participation in PHC can be identified in the immunisation drives and the pit toilet building projects in 1988 and 1989 (public health approach). The health planning approach is identified in the employment and training of community members as family planning motivators, community development officers and community health workers (CHWs). The health planning approach is also identified in the decision-making process. The medical students had initiated and elected the Muldersdrift Clinic Health Committee through which they sought community advice and taught the community participants, through a dialogue, but ultimately they retained the power over decision-making. As Gaede, (1994:49) reports: "In 1989, a number of projects with participation from the community members, were initiated. Attempts were made to run crèches, parents meetings, women's groups and income generating groups. Food gardens and first aid training were tried. But none of the projects lasted longer than 6 to 8 months. The majority failed because the control and maintenance of the projects was entirely dependent on the students."

It wasn't until the nursing science students took over the MHDP at the end of 1995 that the 'people-centred' or empowerment approach to community participation was fully explored and implemented in 1996. In this approach the root causes of health problems are seen as being mainly political as the need 'to empower' people acknowledges that their low status has resulted from continued oppression by society (Wallerstein, 1992 in Mokwena, 1997:67). Swanepoel (1997:7) stated that empowerment means the acquisition of power and the ability to give it effect and it manifests in groups of people working together. Community participation is seen as a way of ensuring equity with the poorest of the poor having the democratic right to participate in decisions affecting his/her development [health] (Gran, 1983:2; also compare Barker, 2003:5). The people-centred/ empowerment approach to community participation is described in Korten's (1990:67) definition of development as; “... a process by which the members of a society increase their potential and institutional capacities to mobilise and manage resources to produce sustainable and justly distributed improvements in their quality of life [or their health in the PHC context] consistent with their own aspirations". This definition implies that the community should have the power and that this power be directed to ensuring an equitable share of the health resources.

Within this approach the MHDP health care providers had to change from the 'top-down' approach to decision-making, where a change agent stimulated community participation, to a 'bottomup' approach where the community acquired the power and drove the planning process. The MHDP with the involvement of the nursing science students became what Korten (1990:498) called an adaptive organisation, which he described as organisations "... with a well-developed capacity for responsive and anticipatory adaptation organisations that: (sic) (a) embrace error; (b) plan with the people; and (c) link knowledge building with action." The MHDP health care providers had to change their role to that of an enabling partner in the community participation process. The intensity of this enablement required adaptation to suit each PHC project's level of community participation. The MHDP health workers 
agreed with Rifkin, et al, (1988) and took as their starting point that health improves through community participation and that broad participation builds on a wide range of $\mathrm{PHC}$ activities and the involvement of many different community groups.

The Muldersdrift community, at an open well advertised meeting in 1996, elected the Muldersdrift Clinic Committee (MCC) with 28 representatives. Each PHC project elected a representative thus ensuring participation of the youth, the senior citizens, women and men's groups. Representatives from each geographical area covered by the MHDP and five community leaders were also elected. The MCC later elected four representatives to represent them on the Joint Management Committee (JMC). The majority of the PHC projects were initiated in partnership with the MCC. Unfortunately this body was disbanded late in 2000 .

As the PHC projects evolved over time, evaluation of the level of community participation achieved, by the participants in each $\mathrm{PHC}$ project, became necessary to guide the intensity of enablement required for each project. Rifkin, et al, (1988:931-940) recognised the need to examine the process rather than the impact of community participation and put forward a framework and methodology, for assessing community participation, which would be applicable to any health care programme. The factors they considered most appropriate, as indicators of community participation, were needs assessment, leadership, organisation, resource mobilisation. management and focus on the poor. They did not include the last factor, as it was difficult to convert into an indicator. For each of the other factors a continuum was developed with wide participation at the one end and narrow participation at the other. Rifkin, et al, (1988:937) stated that the indicators' value is two-fold. Firstly, the indicators' describe differences in community participation over time and by different people. Secondly, they stimulate discussions about community participation, which can help the people involved in the programmes to understand the process better and thus assist them to achieve better results by allowing for greater involvement.

Chetty and Owen (1994:1-12) analysed these ranking criteria and applied them theoretically to a number of PHC projects and found the criteria too broad, subjective, conflicting and neglectful of important details relating to the process of participation, which led to difficulties in interpretation. They took up the challenge to expand Rifkin's, et al, (1988) work to develop criteria, for evaluation, which could be adapted to local South African conditions. They agreed with Rifkin, et al, (1988) on the dual value of the indicators.

\section{Research problem}

A plethora of PHC projects had evolvement from the community members involved in the MHDP from 1992, but there was a lack of information on the exclusivity of the community participation, as well as a lack of information on how much community ownership there was over decisionmaking and resources. Thus at the start of the Joint Management Committee's era of management, the problem was a lack of data on the level of community participation within the MHDP. This problem leads to the research question that the research study sought to answer: "What was the level of community participation in Primary Health Care projects of the Muldersdrift Health and Development Programme?"

\section{Research aim and objectives}

The aim of the research was to measure and describe the level of community participation in PHC projects of the Muldersdrift Health and Development Programme.

Based on the overall aim of the study the research objectives were:

1. To evaluate community participation in the following PHC initiatives in the Muldersdrift Health and Development Programme:

- $\quad$ The Joint Management Committee (JMC).

- The Muldersdrift Clinic Committee (MCC).

- The Elandsdrift Parents/

Teachers Association's

'Thusannang Pre-school Project'.

- $\quad$ The Muldersdrift Home Trust Foundation's 'Our Hope (Thembaletu) in Diamond Park Housing Project'.
The Rietfontein Village Association's 'Water Project'. The Ladies Income-generating 'Sewing and Crochet Project'. The Lesedi Youth Association's Income-generating 'Basket Weaving Project'.

Each PHC initiative's level of community participation will also serve as baseline data for the JMC; the WRRO health care workers; the MCC and the various project members against which future evaluations of the same projects could be measured.

2. To provide the project partners with motivational affirmation on the level of community participation criteria thus far achieved.

3. To indicate to the participants the mechanisms that should still be implemented (criteria still to be achieved) if they are to advance to higher levels of community participation on their own community health and development pathway.

4. To evaluate the MHDP's implementation of peoplecentred approach to community participation in $\mathrm{PHC}$ by evaluating the collective level (sum of all the results) of community participation in the five sampled PHC projects.

5. To evaluate the collective level (sum of all the results) of the seven sampled community participation projects in Muldersdrift (five projects and the two management structures).

\section{Definitions}

- $\quad$ People-centred approach to community participation

The people centred approach, or the empowerment approach as it is also called, is "... a process by which the members of a society increase their potential and institutional capacities to mobilise and manage resources to produce sustainable distributed improvements in their quality of life consistent with their own aspirations" (Korten, 1990:67). A people-centred approach is one of the radical development approaches and argues that participation can only be effective if it is community driven (bottom-up), with the 
community in control to decide about their own affairs and to develop the ability to manage and utilise local resources for their own benefit (Barker, 2003:13).

\section{- $\quad$ Primary Health Care}

The ANC National Health Plan (1994:20) adopts the definition of PHC as defined in the Alma-Ata Declaration. It reads: "Primary Health Care is essential health care based on practical, scientifically sound and socially acceptable methods and technology made universally accessible to individuals and families in the community through their full participation and at a cost that the community and country can afford to maintain at every stage of their development in the spirit of self-reliance and self-determination. PHC forms an integral part, both of the country's health system and overall social and economic development of the community. Central to the PHC approach is full participation in planning, provision, control and monitoring of services (NHP, 1994:9).

\section{- Partnership}

Stanhope and Lancaster (1988:257) define partnership "as the informed, flexible, and negotiated distribution of power among all participants in the process of change for improved community health". In this research study the partnership concept, as defined by Stanhope and Lancaster is applied throughout. One of the covert outcomes of the community participation evaluation is to provide the project partners with motivational affirmation of the level of community participation thus far achieved (Barker, 2003:18).

\section{Research design and - method}

The research design was evaluative, descriptive, quantitative and contextual. The research design was evaluative in nature in that the study found out how well the MHDP's policy of community participation (the people-centred approach) was implemented utilising Chetty and Owen's (1994:1-12) evaluation instrument entitled "Criteria to evaluate Community Participation in Primary Health Care Projects." The research design was descriptive as it portrayed the characteristics of the community participation process. It was quantitative as it measured the level of community participation by counting the criteria chosen by the respondents. However quantitative analytical procedures were not used to describe the phenomena. The results were presented descriptively.
It was contextual in that the results could be generalised outside of the specific $\mathrm{PHC}$ projects within the MHDP.

The MHDP had a study population of twenty-three $(\mathrm{N}=23)$ PHC projects. A purposive sample of seven $(n=7)$ PHC initiatives (the two management structures and five $\mathrm{PHC}$ projects) in the MHDP (in 2000) was chosen according to specified criteria. The criteria for inclusion were the following. That:

- The PHC initiative had as its aim the enhancement of the health and/or development of the Muldersdrift community.

- The PHC management structure had community participants participating with health professionals to enable community participation in PHC. This was determined by the fact that the project:

$\square \quad$ had a MHDP staff member serving as an enabling member of the project committee, and/or

$\square \quad$ utilised the

Muldersdrift

Programme facilities for meetings and/or

$\square \quad$ activities and/or

$\square \quad$ had a committee member serving on the MCC.

- $\quad$ The PHC project had a

functional project committee that consisted of office bearers (Chairperson, Vie-Chairperson, Secretary, Treasurer and a Project Liaison Officer) and at least three ordinary members.

- The PHC project committee had at least one member who had achieved Grade 12 English. The rationale for this was that at least one member had to be able to understand and complete the tool on behalf of the project committee.

In order to demonstrate the extent of the community participation in the $\mathrm{PHC}$ projects chosen, the total membership of each project is presented together with the selected sample and the final sample (refer to Table 1).

The projects were evaluated against Chetty and Owen's (1994:1-12) quantitative instrument entitled 'Criteria to evaluate Community Participation in PHC Projects." A pilot study was undertaken to test both the two research assistants' and Muldersdrift communities' understanding of Chetty and Owen's (1994) standard evaluation instrument. The evaluation tool was found to be understandable to all after a few ambiguous words were defined for clarity.

Structured group interviews were conducted with the PHC projects' executive committee members utilising Chetty and Owen's (1994) evaluation instrument as basis. Validity and reliability were ensured according to the criteria prescribed by Polit and Hungler (1997:657). Data collection was simple as the range of criteria for each component made it easy to choose, by majority vote, after group discussion, the most applicable criteria. The data was quickly and easily analysed and the results fed back to the respondents immediately. The level of community participation attained was pictorially displayed (refer to Figure 1, Figure 2 and Figure 4) and explained. The discussions served to inform the participants about the factors influencing community participation and that the results should not be seen as a score but as an indicator of their increased (broadening) capacities and power over decision-making and resources in order to improve their health and life styles. The component scores achieved by each project's participants were contextually discussed at the end of each interview to provide motivational affirmation for the project's participants. The criteria still to be attained, in order to broaden community participation to the next level, was then identified and discussed within the context of each project.

The Joint Management Committee's (JMC) data was collected via mailed selfadministered questionnaires as Chetty and Owen's (1994) instrument was equally applicable as a questionnaire. This method was considered best for the JMC as they would score more honestly when alone with anonymity ensured and it would minimise the time imposition on these busy professional officials. A report detailing the results was submitted to the JMC.

Data analysis was not difficult as the three component scores obtained were averaged to give the score for that factor which was then plotted on the relevant 
Table 1. Sample selection process and final sample

\begin{tabular}{|l|c|c|c|}
\hline $\begin{array}{l}\text { Community participation PHC Initiative } \\
\text { chosen }\end{array}$ & $\begin{array}{c}\text { Total membership of the } \\
\text { PHC Initiative }\end{array}$ & Selected Sample & Final Study Sample \\
\hline 1. JMC & 12 & 12 & 9 \\
\hline 2. MCC & 28 & 28 & 15 \\
\hline 3. Thusannang Pre-school project & 120 & 8 & 5 \\
\hline 4. MHTF & 300 & 8 & 8 \\
\hline $\begin{array}{l}\text { 5. The Rietfontein Village association } \\
\text { 'Water Project' }\end{array}$ & $600-650$ & 8 & 6 \\
\hline 6. The Ladies 'Sewing and Crochet Project' & 9 & 9 & 4 \\
\hline 7. The Lesedi Youth Association & 18 & 7 & $\mathbf{N}=\mathbf{5 2}$ \\
\hline Totals (n=7) & $\mathrm{N}=\mathbf{1 0 8 7 - 1 1 3 7}$ & $\mathbf{6 8}$ & 9 \\
\hline
\end{tabular}

radiating arm continuum. Each factor's continuum was connected in a spoke configuration, which brought them together at the base where participation was at its most narrow. By connecting the factor score on each continuum a spider graph or web graph was produced. In order to reflect the variations that often existed between different components a graphical representation of the average scores for each component was used, i.e. bar graph. The level of community participation in the MHDP is expressed by the sum of the scores for the seven $(n=7)$ groups and is visualised by use of graphs.

\section{Ethical considerations}

The study complied with the Code of Ethics on Human Subjects (Medical) of the University of the Witwatersrand and was unconditionally approved (Clearance Certificate Protocol Number M980507). The criteria of informed consent of the respondents and participants were adhered to inclusive of principles of respect, dignity, confidentiality, voluntary participation and anonymity. Specific informed consent was obtained from people who appeared in photographs. Written approval (dated 21 November 2002) was also obtained from Dr K Chetty and Prof $P$ Owen to utilise their evaluation instrument entitled "Criteria to evaluate Community Participation in Primary

Figure 1 Comparative levels of community participation achieved by the PHC projects of the Muldersdrit Health and Development Programme.
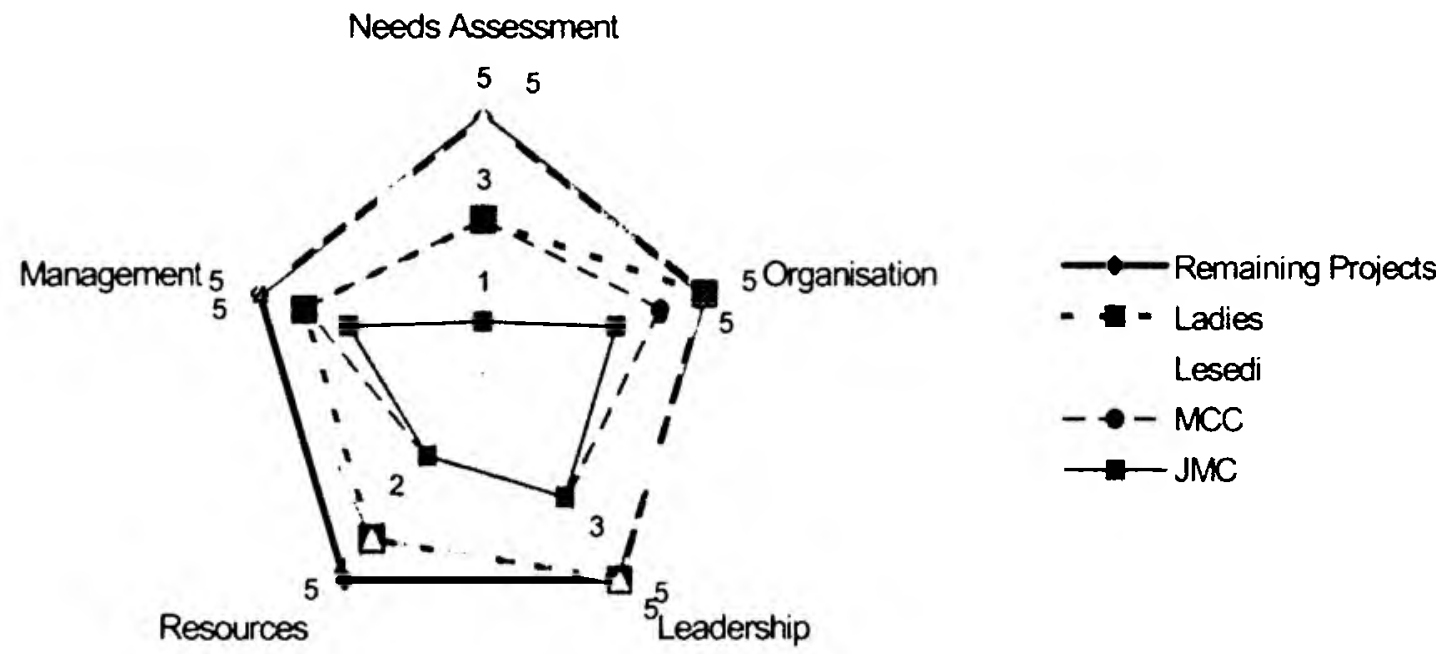
Factor: Resource mobilisation by the Ladies Project Members

\begin{tabular}{|l|l|}
\hline Component & To achieve level 5: \\
\hline $\begin{array}{l}\text { Raising funds and/or } \\
\text { resources }\end{array}$ & $\begin{array}{l}\text { Committee/community members should take the } \\
\text { leadership role in raising funds. }\end{array}$ \\
\hline $\begin{array}{l}\text { Resources mobilised } \\
\text { from the community }\end{array}$ & $\begin{array}{l}\text { Level 3 = Moderate amounts raised by committee. } \\
\text { Level 4 = Large amount of resources raised. Evidence } \\
\text { of community voluntarily offering resources. } \\
\text { Level 5 = Large amounts raised by means of regular, } \\
\text { planned fund raising initiatives and/or there is a regular } \\
\text { source of funds. }\end{array}$ \\
\hline
\end{tabular}

Factor: Management by the Ladies Project Members

\begin{tabular}{|l|l|}
\hline Component & Toachievelevel 5: \\
\hline $\begin{array}{l}\text { Management by the } \\
\text { committee }\end{array}$ & $\begin{array}{l}\text { Level } 4=\text { Committee self-managed, taking } \\
\text { responsibility for the greater part of management. } \\
\text { Level 5 = Committee/group should become self } \\
\text { managed. Appropriated utilisation of experts. }\end{array}$ \\
\hline Skills development & $\begin{array}{l}\text { Level 5 = Skills development programmes extent } \\
\text { beyond the project to community members. }\end{array}$ \\
\hline
\end{tabular}

Factor: Needs and Skills Assessment of the Ladies Project Members

\begin{tabular}{|l|l|}
\hline Component & To achieve level 5: \\
\hline Initial needs assessment & $\begin{array}{l}\text { Community members in general are involved in needs } \\
\text { assessment }\end{array}$ \\
\hline Skills identification & Active identification and utilisation of all skills \\
\hline $\begin{array}{l}\text { Ongoing research and } \\
\text { evaluation }\end{array}$ & $\begin{array}{l}\text { Community/committee utilises own skills to identify } \\
\text { and carry out research. Researchers are used in an } \\
\text { advisory capacity. }\end{array}$ \\
\hline
\end{tabular}

Table B Factor: Resource mobilisation by the Lesedi Youth Association's Committee

\begin{tabular}{|l|l|}
\hline Component & To achieve Level 5: \\
\hline $\begin{array}{l}\text { Raising funds and/or } \\
\text { resources }\end{array}$ & $\begin{array}{l}\text { Level 5 = Committee members take the leadership role } \\
\text { in raising funds. The committec had raised seed money } \\
\text { from Department of Social Services but needed to } \\
\text { become self-sustaining by raising monies through } \\
\text { continued productivity of high quality products and } \\
\text { funds by developing marketing strategies to increase } \\
\text { their turnover and sales. }\end{array}$ \\
\hline $\begin{array}{l}\text { Resources mobilised } \\
\text { from the community }\end{array}$ & $\begin{array}{l}\text { Level } 5=\text { Large amounts should be raised by means of } \\
\text { regular, planned fund raising initiatives and/or a regular } \\
\text { source of funds. }\end{array}$ \\
\hline $\begin{array}{l}\text { Control over allocation of } \\
\text { resources }\end{array}$ & $\begin{array}{l}\text { Level } 5=\text { Committee has total control over allocation } \\
\text { and utilisation of funds. By becoming self-sustaining } \\
\text { the project would not have to be accountable to the } \\
\text { Department of Social Services. }\end{array}$ \\
\hline
\end{tabular}

Health Care Projects".

\section{Discussion of the results}

The results are presented in accordance with the set objectives ( 1 to 5 ). The comparative graph (refer to figure 1) shows the levels of community participation achieved by the five PHC projects.

The Elandsdrift Parents/Teachers Association's 'Thusannang Pre-school Project' (Elands), the Muldersdrift Home Trust Foundation's Our Hope (Thembaletu) in Diamond Park Housing Project' (MHTF), and the Rietfontein Village Association's 'Water Project' (Rietfontein) all achieved an averaged level 5. This represents the widest level of community participation. However as can be seen in the breakdown of the component scores, a few criteria had still to be achieved by these project participants to achieve all of the possible 15 scores/factor (refer to table 1). The Lesedi Youth Association's Incomegenerating 'Basket Weaving Project' (Lesedi) achieved level 5 for all factors except resources mobilisation for which level 4 was achieved. The Ladies Incomegenerating 'Sewing and Crochet Project (Ladies) achieved an averaged level 4.

Analysis of the component scores (refer to table 2) achieved by the participants identified both the criteria (as delimited by Chetty and Owen's [1994] instrument) to be contextually discussed with the project participants/respondents in order to provide them with motivational affirmation of their achievements and to indicate to them the mechanisms (criteria) they would have to implement to achieve broader participation.

The Ladies Income-generating 'Sewing and Crochet Project' were provided with the following motivational affirmation of their achievements. The Ladies had formed a broadly representative committee with majority decision making amongst the members (level 5). Their leader had been elected and was supported by the majority, she did not dominate and allowed and encouraged leadership in the members (level 5). The criteria as shown in Table A had still to be achieved if the Ladies were to achieve broader community participation.

The Lesedi Youth Association's Committee members still needed to achieve the criteria in Talbe B. 
The results of objectives 4 and 5 will be presented concurrently. The level of community participation in $\mathrm{PHC}$, in the MHDP is graphically represented (refer to figure 2). These results were achieved by evaluating the seven sampled community participation initiatives in the MHDP (the five projects and the two management structures).

The level of community participation achieved by the PHC initiatives, of the MHDP, is an averaged level 4. This represents considerable achievements by the MHDP in broadening community participation within the PHC initiatives. The level for each factor presented above (refer to figure 2) was derived from the average of the composite component scores (average of the component scores of all seven of the PHC initiatives sampled) with the result that part-scores occurred (refer to figure 3 ).

The levels presented (refer to figure 2) require further clarification as the lower scores achieved by the Muldersdrift Clinic Committee and the Joint Management Committee diminished the scores achieved by the PHC projects appreciatively. Comparison of the component scores for each PHC initiative (refer to table 2) identified that these structure's scores were lower than the PHC projects in all components. In order to demonstrate these differences, the scores achieved by these parties are re-presented in Figure 4 (refer to figure 4).

The averaged scores of the five $(n=5)$ PHC projects presented in Figure 4 represents the MHDP's level of community participation enabled by the people-centred approach to community participation in PHC projects. The broad levels of community participation (averaged level of between 4 and 5) indicate that the people-centred approach to community participation was successful in empowering the Muldersdrift community participants of the PHC projects. In comparison the Muldersdrift Clinic Committee achieved slightly lower levels at between levels 3 and 4. The Joint Management Committee achieved between levels 2 and 3 .

The Muldersdrift PHC project participants, who were represented on the Muldersdrift Clinic Committee, were able to broaden their community participation to between levels 3-4 (average 3) and through the process they increased their institutional capacities, but they had minimal success in forcing a shift in power over decision making and resources (refer to table 2). This previously very active committee, who had been so productive in broadening community participation through a wide range of PHC projects involving many different community groups, had lost the power they had when enabled by the WITS Department of Nursing Education. In addition the results of the Joint Management Committee indicate that the Muldersdrift community representatives were not empowered and they felt they had no power. The Committee was disbanded in the latter part of 2000 apparently due to disinterest on the part of the members. This demonstrates the importance that the power over planning and resources must be in the hands of the community participants if community participation is to be sustained.

The people-centred approach to community participation enabled the Muldersdrift

PHC project community participants (five $[n=5]$ sampled) to broaden community participation to between levels 4 to 5 (averaged 5) [refer to figure 4]. This community-based, radical developmental approach, implemented under the auspices of the Department of Nursing Education, had enabled the community by authorising the acquisition of power by the community and by ensuring that they had the necessary knowledge,

Table 2. The component scores of the seven PHC initiatives of the Muldersdrift Health Development Programme

\begin{tabular}{|l|l|l|l|l|l|l|l|l|}
\hline & & Elands. & MHTF & Ladies & $\begin{array}{l}\text { Rietfon- } \\
\text { tein }\end{array}$ & Lesedi & MCC & JMC \\
\hline \multirow{2}{*}{ ORGANISATION } & Formation of Committee & 5 & 5 & 5 & 5 & 5 & 5 & 3.5 \\
& Decision making & 5 & 5 & 5 & 4 & 5 & 2 & 3 \\
& Accountability & 5 & 5 & 5 & 5 & 5 & 5 & 3 \\
\hline \multirow{2}{*}{ LEADERSHIP } & How Chosen & 5 & 5 & 5 & 5 & 5 & 2 & 3.3 \\
& Allowing Participation & 5 & 5 & 5 & 4 & 5 & 5 & 4.6 \\
& Role of Other Members & 5 & 4 & 5 & 5 & 5 & 2 & 3.3 \\
\hline \multirow{2}{*}{ RESOURCES } & Raising Resources & 4 & 5 & 4 & 5 & 4 & 2 & 2 \\
& Resources from the Community & 5 & 5 & 2 & 5 & 4 & 2 & 3 \\
& Control over resource allocation & 5 & 5 & 5 & 5 & 4 & 3 & 1.6 \\
\hline \multirow{2}{*}{ MANAGEMENT } & By Committee & 5 & 5 & 3 & 5 & 4 & 3 & 2.3 \\
& By Staff & 5 & 4 & 5 & 5 & 5 & 3 & 2 \\
& Skills Development & 5 & 5 & 4 & 5 & 5 & 5 & 3.3 \\
\hline \multirow{2}{*}{ NEEDS \& SKILLS } & Initial Needs Assessment & 4 & 5 & 3 & 5 & 5 & 4 & 1.6 \\
& Skills Identification \\
& Ongoing Research and Evaluation & 5 & 5 & 3 & 4 & 4 & 2.5 & 1.6 \\
& & & 5 & 5 & 5 & 5 & 1 \\
\hline
\end{tabular}


Needs/Skills

Assessment

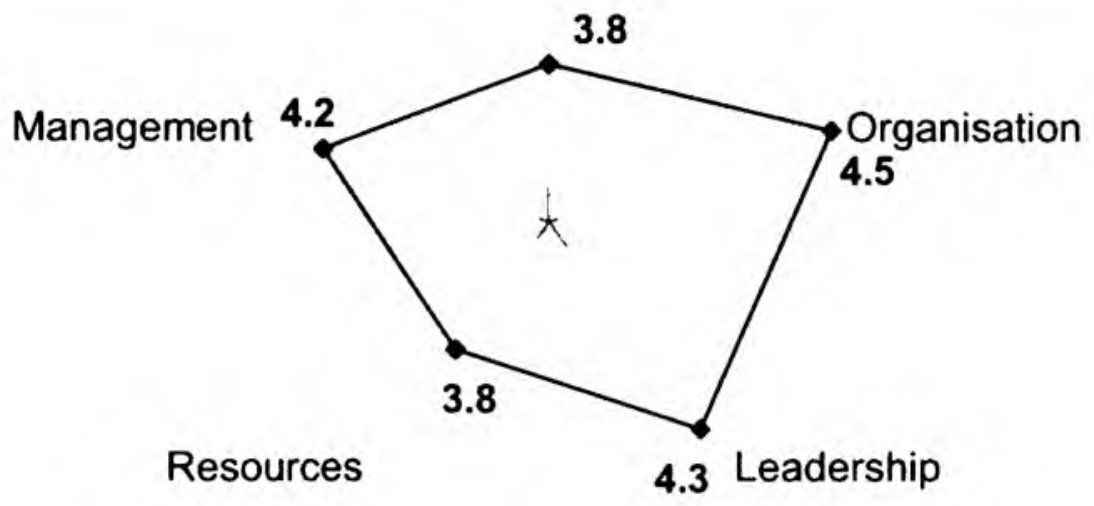

understanding and institutional capacities to identify their needs and to make the correct decisions relating to their health care. The community was also partnered in their acquisition of power and institutional capacities to mobilise and manage resources or to force a shift in resources so as to produce sustainable and justly distributed (equitable) improvements in their quality of life, consistent with their own aspirations. This approach has empowered the community participants in the MHDP's PHC projects to a level, where they will be able to implement the community participation process on their own using health professional/experts as resources. However the level 4 for resource mobilisation indicates that enablement of a resource authority and experts was still required.

The Joint Management Committee achieved minimal broadening in community participation to levels 2 to 3 (averaged 2.5) that indicates that the health professionals held the power over resources and took all the decisions. The health professionals/resource holders recognised that they dominated the community representatives in decision making and management. The JMC members perceived that the Muldersdrift representatives had minimal power over resource allocation

(Component level 1 to 2) [Refer to table 2]. Assessment of community and skills were confined to the researchers/ resource authority. This indicates that the JMC was not committed to community participation. Rifkin's (1981) public health approach to community can be identified in the JMC's results. The Muldersdrift community leaders were elected to meet policy requirements; however the health professionals due to their expert knowledge retained the power over decision-making, resources and the identification of needs and skills assessment.

The narrow levels (averaged level 2.5) of community participation in the Joint Management Committee and the Muldersdrift Clinic Committee (averaged level 3 ) indicate that the MHDP's peoplecentred approach to community participation had not been adopted by the health professionals/resource authority responsible for the MHDP. The three partners i.e. the WRRO, WITS and the Muldersdrift representatives, had not discussed the concept community participation and identified that they had different approaches to community participation. They had not come to a consensus and made their choice of an approach to community participation explicit.

The PHC projects component scores (refer to table 2) identified that there were community leaders who tended to dominate and did not allow all the members to participate or only consulted and reported back to the committee on an ad hoc basis. Community leaders who dominate, who do not consult and who are not accountable to the group, and who were elected to lead, do not contribute to community participation. Such leaders are a danger to community participation as they depolarise the power from the poor and disadvantaged that they are meant to be leading on the path to empowerment. Such leaders have to be debunked for community participation to be successful. Chetty and Owen's (1994) evaluation instrument is an effective debunking tool as it identifies the criteria required by empowering leaders to broaden participation. As the community participants evaluate their projects, utilising the Chetty and Owen tool, they learn about the qualities of good leaders 
Figure 3. The MHDP's composite component scores.

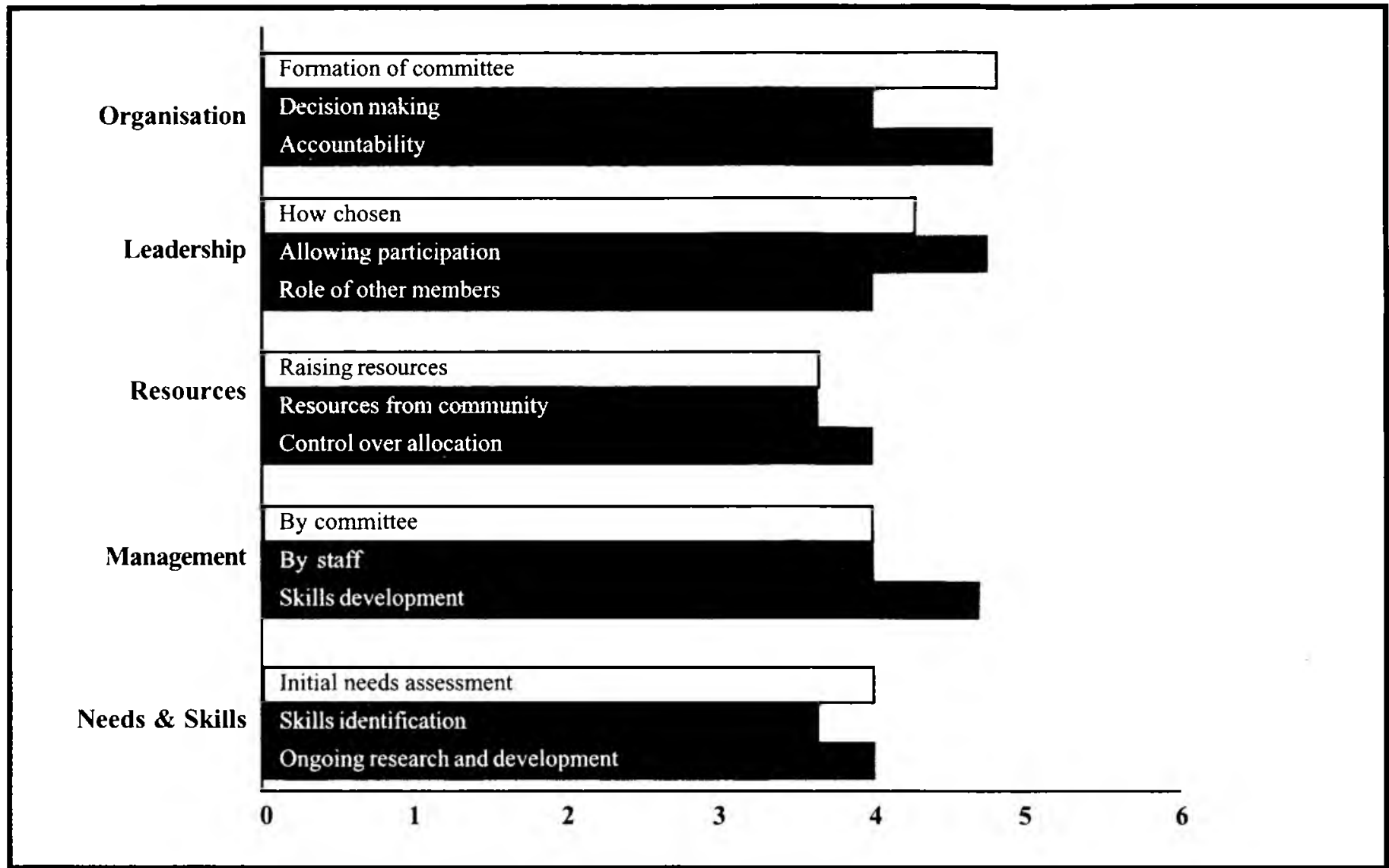

for example not to dominate, to engender active leadership by all committee members, to develop skills beyond the project of community members and to be accountable to both the committee and the project members.

\section{Conclusion}

The study sought to answer the question: "What was the level of community participation in Primary Health Care projects of the Muldersdrift Health and Development Programme? The question was answered, the aims of the study were met by measuring the community participation achieved by the participants of seven $(n=7)$ PHC projects of the MHDP by using Chetty and Owen's (1994) evaluation instrument. The set objectives were all achieved.

Chetty and Owen's (1994) instrument entitled 'Criteria to evaluate Community participation in Primary Health Care Projects' was chosen as it expanded Rifkin's, et al,. (1988:936) assessment tool to suit South African conditions. The instrument was designed to evaluate individual projects but this study had extended its use to multiple projects within a programme. In extending its function evaluation was significantly improved by analysing results of the component scores and comparative factor level graphs. Chetty and Owen's evaluation instrument is recommended for the evaluation of community participation in individual $\mathrm{PHC}$ projects and for multiple $\mathrm{PHC}$ projects within a PHC programme. The study results confirmed the findings of Chetty and Owen (1994:3) that the instrument is valuable in providing feedback to the $\mathrm{PHC}$ project participants on their achievements and as a guide to the mechanisms they would have to take to achieve the next level. The intention of the tool is to evaluate the participation level of projects, however it is anticipated that through the evaluation, community participation will be enhanced and project members will be motivated to improve over time.

\section{Limitations}

The limitations identified in the study, were:

- $\quad$ The study evaluates the overt outcomes of community participation and presumes that, by affirming the level of participation achieved by the members of each $\mathrm{PHC}$ project the covert outcomes of development, i.e. enhanced selfesteem, dignity, and a sense of ownership, is achieved. Chetty and Owen's (1994) instrument evaluates the PHC project's committee thus the executive committees of the sampled projects were evaluated. The results are thus restricted to the level of community participation attained by the executive committee members in the project. Executive members are usually elected because the community perceives that they will do a good job, thus they already possess some skills. In future as many $\mathrm{PHC}$ projects members as possible should be included in the evaluation to prevent this potential bias.

- The results cannot be generalised outside of the specific PHC projects and management structures (MCC and JMC) within the MHDP.

\section{Recommendations}

Within the Muldersdrift Health and Development Programme It is recommended that $\mathrm{CHNs}$ responsible for the MHDP should lobby for the following changes if the levels of 
Figure 4. Comparative graph of the levels of community participation achieved by the Joint Management Committee, the Muldersdrift Clinic Committee and the averaged level of the five PHC projects enabled by the Muldersdrift Health and Development Programme.

\section{Needs Assesssment}

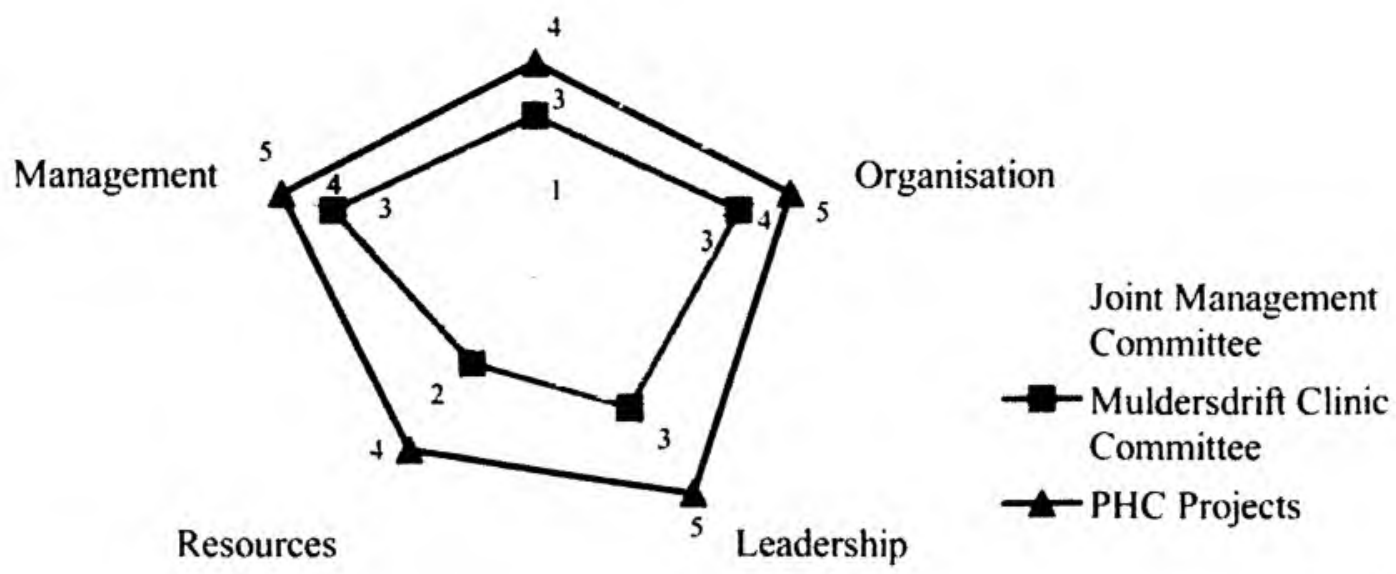

community participation in $\mathrm{PHC}$ are to broaden:

- The JMC's members, jointly, should have authorised power over resources allotted to them annually by the Gauteng Department of Health. The financial allotment should include sufficient funds for both health care provision and development.

- The health professionals, the health resource authority and the Muldersdrift community representatives should discuss their approach to community participation to ensure commitment to the projects.

- For professional health care decisions, the community representatives on the JMC should be provided with sufficient information to empower them to make informed decisions.
Committee should be reformed to provide the PHC project members with a forum to: (i) assess community needs, skills and aspirations, and conduct ongoing research; (ii) conduct strategic planning for the broader community; (iii) enable lobbying from a position of strength (in numbers) and moral support; (iv) provide the line of communication to and from the JMC; (v) provide education and skills training; and (vi) the committee should be allocated an annual budget for community participation/ development and authorised legal control over allocation of the resources for which they will be held accountable.

\section{Recommendations for CHN's} to enable community participation' practice It is recommended that $\mathrm{CHN}$ use the theoretical framework and the concept 'enabling resources' and implement the following recommendations:

- $\quad$ Evidenced based nursing practice. Evaluation of the level of community participation attained by project participants is essential. Firstly, assessment is the first step in any nursing action and secondly, knowledge of the level of community participation will guide the CHN's practice i.e. guide the intensity of enabling resources offered by the nurse for that project. The evaluation process draws the nurse's attention to the fact that, as the level of community participation broadens the more the CHN's role changes to that of a health resource person, when consulted by the community. CHNs are to ensure that they remain responsible for comprehensive health care, i.e. preventive, curative and rehabilitative PHC which includes community development and thus community participation. The $\mathrm{CHN}$ is in a managerial position responsible for the health of the community thus both 'downstream'/episodic health care and 'upstream' endeavours are her concern. Delegation of community participation in $\mathrm{PHC}$ (community development) to Health Promoters, who are both 
trained and close to the community, is recommended but only if managed by the CHN.

The CHN offer 'enabling resources' to the community who will only access this 'enablement' if they know the 'what, where, when and how' of these resources. The $\mathrm{CHN}$ needs to market this 'enablement'. The lesson learned at MHDP is that the regular community events needed to vary for example one month something recreational the next something serious i.e. budgeting. The lessons learned from organising the recreational activity for example traditional dance contest could be used at the basis for the next months budgeting lesson i.e. fun, reality based, need orientated learning activities motivated more and more community participation.

\section{Recommendations for nurse} researchers in community participation

It is recommended that Community Health Nurses utilise Chetty and Owens (1994) Evaluation Instrument entitled "Criteria to evaluate Community Participation in Primary Health Care Projects" to assess the level of community participation achieved in every PHC project they participate in / partner. Research recommendations include the following:

- Assessment of community participation at the initiation of $\mathrm{PHC}$ projects to establish a baseline against which future broadening of community participation can be measured. Evaluation at regular intervals should be conducted to provide motivation and to utilise the instrument's criteria as a proactive guide towards broader participation. As projects are so different each project's participants should choose their own concurrent evaluation intervals. Broader community participation results in increased potential and institutional capacities to mobilize and actively participate in identifying their own needs, skills and aspirations eventually only using $\mathrm{CHN}$ rescarchers in advisory capacity.

Assessment should be

conducted at the end of a

project to establish summative

evaluation of community

participation.

Evaluation of their participation would affirm their

developmental gains and enhance their dignity which in turn motivates continuing community participation.

- $\quad$ Research is recommended to evaluate the subjective outcomes of community participation.

\section{Recommendations for nurse leaders/administrators} The study identified the following recommendations: $\mathrm{CHNs}$ in PHC management positions to have advanced education and training.

- Trust/partnership building time should be considered as onduty time. Initial contact and trust building with a community takes time spent attending community meetings, social events, funerals and political rallies.

\section{Recommendations for nurse} educators of $\mathrm{CHNs}$

This study has identified that CHNs will require training, by nurse educators, and additional skills to equip them to enable community participation in PHC. It is recommended that the following requisite 'enabling' skills are either added to or enhanced in the curricula both for basic $\mathrm{CHN}$ education and training and in postgraduate CHN/PHCN cducation:

- $\quad$ Communication skills

- Organisational skills

- $\quad$ Leadership development skills

\section{Acknowledgement}

This study was completed at the Department of Nursing Education, while the second author was a fulltime employee at the University of the Witwatersrand. The article was finally prepared for publication with the assistance of Ms Petro Bester and Ms Ronel Pretorius, $\mathrm{PhD}$ candidates and research assistants at North-West
University.

\section{References}

ANC, 1994: A National Health Plan (NHP) for South Africa. Johannesburg: African National Congress.

BARKER, MJ 2003: Level of Community participation in Primary Health Care projects of the Muldersdrift health and development programme in 2000. M Sc dissertation: University of the Witwatersrand.

BOTES, A 1991: A Functional Approach in Nursing (' $n$ Funksionele denkbenadering ' $n$ die Verpleegkunde). Curationis, 14 (1), pp. 19-23.

CHETTY, K \& OWEN, P 1994: Criteria to evaluate community participation in Primary Health Care Projects. Cape Town: Department of Community Health, University of Cape Town.

GAEDE, B 1994: Social Change and Service Development. A Newly Urbanising Community. Critical Health, 46, pp.47-52.

GRAN, G 1983: Development by People: Citizen Construction of a Just World. New York: Praeger

KORTEN, DC 1980: Community organisation and rural development: a learning process approach. Public Administration Review, 40 (5), pp. 498502

KORTEN, DC 1990: Getting to the $21^{\text {st }}$ century: voluntary action and the global agenda. West Harford: Kumarian.

MOKWENA, K 1997: Empowerment as a Tool for Community Health Development. CHASA. Journal of Comprehensive Health, 8(2), pp. 66-70.

POLIT, DF \& HUNGLER, BP 1997: Nursing Research principles and method. J.B. Lippincott Company

RIFKIN, SB 1981: The role of the public in the planning, management and evaluation of health activities and programmes, including self-care. Social Science Medicine, 15, pp. 377-386.

RIFKIN，SB; MULLER，F\& BICHMANN, W 1988: Primary Health Care: on measuring participation. Social Science Medicine, 26 (9), pp. 931-940. 
RIFKIN, SB \& CASSELS, A 1990:

Training managers for primary health care: teaching about community involvement. Medical Teacher, 12 (1), pp. $39-45$.

STANHOPE, M \& LANCASTER, J 1988: Community Health Nursing. Process and Practice for Promoting Health. St. Louis: The CV Mosby Co.

SWANEPOEL, H 1997: Community Development. Putting plans into action. $3^{\text {rd }}$ edition. Cape Town: Juta \& Co.

UNIVERSITY OF THE WITWATERSRAND, 1984: Muldersdrift Health Centre: Constitution. Johannesburg: University of the Witwatersrand.

WORLD HEALTH ORGANISATION, 1978: Alma-Ata 1978: Primary health care. Report of the International Conference on Primary Health Care AlmaAta, USSR, 6-12 September 1978. Health for All Series, No. 1. Geneva: WHO. 